\title{
Breast Cancer Systemic Therapy: The Need for More Eco- nomically Sustainable Scientific Strategies in the World
}

\author{
Ahmed Elzawawy a, b, c, d, e \\ ${ }^{a}$ Clinical Oncology Department, Faculty of Medicine, Suez Canal University, ${ }^{b}$ Alsoliman Radiation Oncology Unit, ${ }^{c}$ Early Detection and \\ Cancer Chemotherapy Unit, Port Said General Hospital, \\ dSEMCO: South and East Mediterranean College of Oncology, Port Said, Egypt \\ eICEDOC \& ICEDOC's Experts in Cancer without Borders, USA
}

\section{Key Words}

Breast cancer - Treatment - Cancer control · Low and middle income countries - Cancer chemotherapy .

Health economics

\section{Summary}

The world-wide incidence of cancer is expected to increase to 20 million by 2020 . $70 \%$ of new cases occur in countries with $5 \%$ of the global cancer control resources. Breast cancer is the most common malignancy among women in high income, as well as low and middle income countries (LMCs). For the leading pharmaceutical companies, the current market for breast cancer systemic therapy (BCST) in LMCs is likely to decline in the future due to increasing costs of novel drugs. Breast cancer provides a strong example for multiple drug management of solid tumors. Development of economically sustainable scientific strategies for BCST in LMCs could improve affordability of therapy for other cancers throughout the world. Examples of recent and ongoing studies using protocols that could decrease costs of treatment without compromising outcomes are reviewed. The Win-Win initiative proposed by ICEDOC's (International Campaign for Establishment and Development of Oncology Centers) Experts in Cancer without Borders starts with small pilot meetings for oncologists with key stakeholders, including leading pharmaceutical companies. The participants would develop a roadmap for actionable strategies for crafting affordable BCST tailored to regional conditions and the diverse populations of women with breast cancer.

\section{Schlüsselwörter}

Brustkrebs · Behandlung · Krebskontrolle · Länder niedrigen und mittleren Einkommens . Krebschemotherapie - Gesundheitsökonomie

\section{Zusammenfassung}

Bis zum Jahr 2020 wird die weltweite Krebsinzidenz voraussichtlich auf 20 Millionen ansteigen. 70\% der neuen Fälle treten in Ländern mit nur 5\% der globalen Mittel zur Krebskontrolle auf. Brustkrebs ist die häufigste Krebserkrankung bei Frauen in Ländern sowohl hohen als auch niedrigen und mittleren Einkommens (low and middle income countries, LMCs). Für die führenden Pharmafirmen wird die derzeitige Nachfrage nach systemischen Brustkrebstherapien (breast cancer systemic therapy, BCST) in LMCs auf Grund der steigenden Kosten neuer Arzneimittel in der Zukunft wahrscheinlich zurückgehen. Brustkrebs ist ein starkes Beispiel für das multiple medikamentöse Management solider Tumoren. Die Entwicklung ökonomisch tragbarer wissenschaftlicher Strategien für BCST in LMCs könnte die Erschwinglichkeit von Therapien für andere Krebsarten weltweit verbessern. Beispiele kürzlich durchgeführter und laufender Studien zu Protokollen, die die Behandlungskosten ohne Beeinträchtigung des Outcomes senken können, werden besprochen. Die von ICEDOCs (International Campaign for Establishment and Development of Oncology Centers) "Experts in Cancer without Borders" vorgeschlagene Win-Win-Initiative setzt bei kleinen Pilottreffen zwischen Onkologen und Hauptinteressengruppen (inklusive führender Pharmafirmen) an. Die Teilnehmer würden dann einen Plan erstellen, der machbare Strategien zur Bereitstellung finanziell tragbarer BCST zugeschnitten auf regionale Gegebenheiten sowie die unterschiedlichen Populationen von Frauen mit Brustkrebs beinhaltet.

\begin{tabular}{ll}
\hline KARGER & $\oplus$ 2008 S. Karger GmbH, Freiburg \\
Fax +497614520714 & Accessible online at: \\
$\begin{array}{l}\text { Information@Karger.de } \\
\text { www.karger.com }\end{array}$ & www.karger.com/brc
\end{tabular}




\section{Introduction}

The global incidence of cancer increased by $19 \%$ in the past decade, primarily attributed to cases in developing or so-called low and middle income countries (LMCs) [1, 2]. By 2020, among the 20 million new cancer patients, $70 \%$ will be located in countries that have, collectively, just $5 \%$ of the global cancer control resources. It is estimated that $60-70 \%$ of the world's cancer patients have no access to systemic cancer chemotherapy. Even fewer people have access to radiotherapy. The picture is especially tragic in Sub-Saharan Africa [1,3-7].

Pharmaceutical companies are developing costly novel cancer drugs largely marketed in the USA, Western Europe, and Japan. There is no indication that the costs of these drugs will diminish in the future [8]. In LMCs, encompassing regions with the majority of the world's population, there is no evidence that more than $5 \%$ of the total number of cancer patients can afford these novel anticancer drugs. By 2020, the increasing expense of therapy using novel agents is likely to decrease access even further. There is no sign that the need for systemic anticancer therapy will decrease. We are therefore confronted with complex challenges that require the collaborative efforts of international and regional partnerships.

This paper proposes a global collaboration among key stakeholders to develop economically sustainable scientific strategies, and mobilize efforts using evidence-based approaches to facilitate accessibility of breast cancer systemic therapy (BCST) in LMCs. Such strategies must consider the diversity of local conditions, resources, ethnicities, and cultures. This could serve as a model for other cancers.

\section{Breast Cancer as a Model}

Breast cancer is the world's most frequently diagnosed cancer among women. The rate of increasing incidence is higher in developing countries [1,9-11]. Locally advanced breast cancer, for which multimodality therapy is the standard of care in developed and high resource regions, represents up to $80 \%$ of all breast cancer cases in LMCs [12]. Breast cancer is an excellent exemplar of common solid tumors, without a predictable decrease in incidence and in which multiple active drugs are available.

\section{Approaches to Cancer Treatment in LMCs}

The cost of cancer treatment is a major element of therapeutic decisions, particularly in LMCs. Innovative evidence-based cancer control and management strategies could diminish the burden of costs [5]. A review of the current literature provides examples of innovative ideas, evidence-based approaches, and ongoing efforts that could decrease the costs of BCST without compromising outcomes.

\section{Resource Level-Appropriate Use of Costly Agents}

The notion of 'resource level-appropriate' treatment necessarily involves inclusion of locally available resources and establishment of viable partnerships. The discussants in the Systemic Therapy Group at the Breast Health Global Initiative (BHGI; October 1-4, 2007 Budapest) noted uses of trastuzumab (Herceptin ${ }^{\circledR}$, Roche Pharma AG, Grenzach-Whylen, Germany) in some LMCs for treatment of patients with metastatic breast cancer and unknown HER2/neu status. It is proposed that relevant pharmaceutical companies fund demonstration projects in selected LMCs for the determination of hormone receptor and HER2/neu status. Limiting the use of trastuzum$\mathrm{ab}$ to women with localized disease and known HER2/neupositive status, as suggested by Yarney et al. [13], is a costeffective approach if resources are available, even with the additional costs of HER2/neu testing. The optimal duration of adjuvant trastuzumab therapy remains undetermined. The FinHer (Finland Herceptin) study indicated that a 9-week period of trastuzumab administration is effective in women with HER2/neu-positive breast cancer [14]. Another trial with 2 arms is comparing 6 months with 1 year of trastuzumab [15]. The Glivec International Patient Assistance Program (GIPAP) provides imatinib (Glivec ${ }^{\circledR}$, Novartis, Basel, Switzerland) at no cost to patients with chronic myelogenous leukemia or gastrointestinal stromal tumors, and to patients in 81 countries, who have no access to Glivec [16]. However, it would be unrealistic to count on pharmaceutical companies for major funding for other drugs.

Potential research questions include the interrupted courses of aromatase inhibitors (AI) that probably would also be effective as continuous therapy after prior tamoxifen and/or AI treatment. The hypothesis is that AI interrupted courses perhaps could enhance response of residual resistant cells [17]. The example of phase I-II trials of low dose gemcitabine in prolonged infusion (of $250 \mathrm{mg}$ and $180 \mathrm{mg} / \mathrm{m}^{2}$ for 6 and $24 \mathrm{~h}$, respectively) and its encouraging results in responding solid cancers like non-small cell lung cancer, breast, pancreas, and bladder cancers could be further investigated. The explanation lies in the saturation of the enzyme deoxcytidine kinase needed for conversion of gemcitabine into its active form gemcitabine triphosphate, which occurs after short conventional infusion and leaves most of the drug unmetabolized [18-22]. Other interesting pharmacokinetic-based studies include the example that showed that lapatinib taken orally with food and beverage containing CYP3A such as grapefruit juice, and not on an empty stomach as stated on the label, results in increased plasma levels and could reduce the dose and costs of lapatinib by $80 \%$ [23].

The use of more oral regimens of several cancer drugs may decrease costs of administration [24-27]. However, the pros and cons need more studies in different communities. The pharmaceutical industry could assist the development of the necessary infrastructure to conduct clinical trials in LMCs 
[13]. Successful collaborations could accelerate drug development, testing, and application time spans through enhanced trial subject accrual while offering patients opportunities to receive standard and investigational agents and contributing to oncology-related professional education and training. Conducted with appropriate ethical guidelines and international oversight, such efforts could provide wider and more transparent access to new agents.

\section{Essential Drugs for Cancer Therapy}

The World Health Organization (WHO) proposed 17 essential drugs required for cancer therapy [28], a list that is currently in its 15th revision [29]. Many drugs included in the 'Essential Drugs for Cancer Therapy' list have generic equivalents that offer the possibility of less expensive treatment. However, quality should not be compromised. International efforts and experts needed to assure the quality of generics delivered to LMCs were proposed during a discussion at the annual meeting of the International Network for Cancer Treatment and Research (INCTR), Sao Paulo, 1-4 March, 2007. Such a program could assure that generic drugs used in LMCs provide outcomes comparable to trade name drugs. Quality generics and original drugs, even at slightly higher costs, could be cost-effective and perhaps lessen the need for expensive second line treatment. Initial reservations surrounding my suggestion were about the feasibility on a large scale. However, development and implementation of small scale pilot programs, at the invitation of few selected LMCs, could assess the usefulness and viability of such a program. In the 2007 BHGI meeting, the Systemic Therapy Focus Group urged to assure bioequivalence of generic drugs.

The conventional cancer drugs constitute the basis of BCST. Recent studies provide evidence to support new indications for these drugs. For example, cisplatin has been shown to be useful in the treatment of triple negative (estrogen receptor, progesterone receptor, HER2/neu 0,1) breast cancer [30]. Varied schedules and modes of administration of the conventional drugs are being explored, like the metronomic use of prolonged, low oral doses of cyclophosphamide and methotrexate as palliative systemic cancer treatment [31].

Recent pharmacogenomic studies suggest that genetic variants of the enzyme CYP2D6 influence the plasma concentration of active tamoxifen metabolites (4-OH tamoxifen and endoxifen) and treatment outcome of breast cancer patients treated with adjuvant tamoxifen [32]. Tamoxifen patients could be classified as poor, intermediate, and extensive metabolizers; CYP2D6 genotypic test results varied in different ethnicities. Europeans tends to have higher extensive metabolizers than Asians [32-35]. Accordingly, CYP2D6 genotyping could open avenues to avoid unnecessary costs of tamoxifen for years. Moreover, strong CYP2D6 inhibitors such as the selective serotonin reuptake paroxetine - used some- times to decrease hot flashes - should be avoided as co-medication [32]. On the other hand, at ASCO 2007, Punglia et al. [36] presented a bio-mathematical model estimating that the benefit of 5 years of adjuvant tamoxifen in postmenopausal patients may even exceed upfront AI treatment in postmenopausal CYP2D6 wt/wt genotype patients. Genotyping could also be important for tamoxifen chemoprevention and its cost-effectiveness [37].

\section{Discussion}

Innovative strategic approaches are imperative for improving access to systemic therapy as a component of breast cancer control, along with primary prevention, early diagnosis, screening, optimal treatment services and symptom control, and palliation in LMCs [28]. Early detection programs are fruitless without accessible treatment [38]. However, national cancer control programs, international and regional meetings, publications, and treatment guidelines are not enough [36]. Guidelines lagged behind plans for accessibly and affordability of treatment in LMCs [39, 40]. Every region has a unique matrix of contributing factors - geography, culture, socioeconomic status, diet, genetic differences and ancestry, and molecular characteristics that are linked to individual and population differences in cancer risks and responses to therapy and optimal implementation of cancer control activities [41]. However, LMCs have many challenges in common. The cost of anticancer drugs may force policy makers and oncologists in LMCs to treat fewer patients with standard regimens copied from rich countries, and to deny treatment to millions of patients. The question is: Do we allow this tragic option to continue? The alternative option proposed in this paper is to develop scientific approaches for tailored and affordable treatments to a larger population without compromising outcomes.

\section{Potential Components of the Win-Win Initiative}

The Win-Win initiative proposed here is on behalf of ICEDOC's Experts in Cancer without Borders (ICEDOC: International Campaign for Establishment and Development of Oncology Centers; www.icedoc.org). ICEDOC does not claim in this initiative any sort of leadership or invention. Collaboration, cooperation; coordination, and harmony between key stakeholders are needed. These efforts could be commenced with pilot meetings of a small number of key stakeholders followed by subsequent larger meetings during which strategies and collaborative actions would be devised. A complete list of strategies and associated descriptions is premature and beyond the scope of this paper. However, viable goals and proposals of strategies are offered here with the intent to stimulate additional thoughts among readers. 


\section{Goal 1}

The first goal is to devise cost-effective treatment guidelines for breast cancer based on clinical, pathological, and biological factors. An example are the gentoyping studies of CYP2D6 prior to adjuvant endocrine breast cancer treatment among different ethnic groups and populations before designing protocols of hormonal treatment and chemoprevention. This would identify patients most likely to benefit (or not) from selected treatment modalities [42]. Strategies involve the tailoring of therapeutic protocols to patients based on clinical, pathological, and biological features.

\section{Goal 2}

The second goal is to promote and facilitate the search for methods to lower the costs of novel drugs without compromising therapeutic outcomes and quality of life. Examples are encouraging early results of shorter duration of treatment with trastuzumab [14] and that of low dose prolonged infusion of gemcitabine [18-22]. Pharmacokinetic studies that pursue ways to enhance bioavailability of agents could markedly decrease the required doses and subsequent cost of treatment [23]. Strategies include the support of clinical trial processes to pursue evidence to support less costly and optimal therapeutic efficacy outcomes.

\section{Goal 3}

The third goal is to enhance investigations of innovative combinations, different schedules, and modes of administration of older drugs in LMCs. At present, investigations of essential drugs are rarely featured in international cancer conferences. Stimulation of industry interest in research on essential drugs in LMCs could create a suitable infrastructure of use of novel agents when properly indicated. Strategies involve the encouragement of the development of innovative cancer control strategies and education that include applications and/or trials using essential cancer drugs.
Cancer research in developing countries remains challenging, owing to inadequate training, the high cost of diagnosis, the need for advanced technologies, and the lack of epidemiological studies [43]. Not only North-South collaboration but also South-South interconnections and cooperation are necessary [44].

\section{Conclusions and Future Directions}

First, the purpose of this publication is to launch the Win-Win initiative proposed by ICEDOC and to create a think tank to foster innovative scientific thoughts aimed at designing costeffective, accessible, and affordable systemic treatment for breast cancer patients - and subsequently to other cancers - in LMCs. Second, the outcome of the communications and small pilot meetings in the years 2008/2009 would formulate a roadmap for the Win-Win initiative: i) actionable strategies open for contribution, collaboration, and coordinating efforts and ideas; ii) formation of a collaborative task force group directed to increase availability and affordability of systemic cancer therapy in LMCs; iii) a published report in a peer reviewed journal; iv) proposal of pilot projects.

Despite that, the motivation of this ICEDOC initiative is largely humanitarian, but it is based on scientifically derived evidence and reflects a 'win-win' scenario in global cancer control.

\section{Acknowledgement}

I thank Prof. Gabriel Hortobagyi and Mrs. Sandra Distelhorst, Breast Health Global Initiative (BHGI), USA, for their advice during editing parts of the manuscript, Prof. Heinz Zwierzina, Austria and cofounder of ICEDOC for the thorough discussion, Pamela J. Haylock, PhD, RN, Secretary General of ICEDOC, Texas, USA for the revision of the text, and Dr. Hossam Elbahaie, Egypt, for his assistance in preparing the manuscript.

\section{References}

1 Stewart BW, Kleihues P: World Cancer Report. Lyon, France, IARC Press, 2003.

2 Yach D, Hawkes C, Gould CL, Hofman KJ: The global burden of chronic diseases: overcoming impediments to prevention and control. JAMA 2004; 291:2616-2622.

3 Jones SB: Cancer in the developing world: a call to action. BMJ 1999;319:505-508.

4 Iarc Working Group on the Evaluation of CancerPreventive Strategies: Iarc Handbooks of Cancer Prevention. Lyon, Oxford University Press, 2002.

5 Sikora K: Developing a global strategy for cancer. Eur J Cancer 1999;35:1870-1877.

-6 Porter A, Aref A, Chodounsky Z, Elzawawy A, Manatrakul N, Ngoma T, Orton C, Van't Hooft E, Sikora K: A global strategy for radiotherapy: a who consultation. Clin Oncol (R Coll Radiol) 1999;11: 368-370.
7 Ashraf H: Poor nations need more help to slow growing cancer burden: the international atomic energy agency asks donors to provide millions of dollars to buy radiotherapy equipment. Lancet 2003;361:2209.

8 Meropol NJ, Schulman KA: Cost of cancer care: issues and implications. J Clin Oncol 2007;25: 180-186.

9 Ferlay J, Bray F, Pisani P, Parkin DM: Globocan 2000. Cancer incidence, mortality and prevalence worldwide, version 1.0, Iarc cancerbase no. 5. Lyon, IARC Press, 2001.

10 Parkin DM, Bray F, Ferlay J, Pisani P: Global cancer statistics, 2002. CA Cancer J Clin 2005;55: 74-108.

11 Porter P: 'Westernizing' women's risks? Breast cancer in lower-income countries. N Engl J Med 2008; 358:213-216.

12 Carlson RW, Anderson BO, Chopra R, Eniu AE, Jakesz R, Love RR, Masetti R, Schwartsmann G: Treatment of breast cancer in countries with limited resources. Breast J 2003;9(suppl 2):S67-74.
3 Yarney J, Vanderpuye V, Clegg Lamptey JN: Hormone receptor and HER-2 expression in breast cancers among Sub-Saharan African women. Breast J 2008;14:510-511.

14 Joensuu H, Kellokumpu-Lehtinen PL, Bono P, Alanko T, Kataja V, Asola R, Utriainen T, Kokko R, Hemminki A, Tarkkanen M, Turpeenniemi-Hujanen T, Jyrkkio S, Flander M, Helle L, Ingalsuo S, Johansson K, Jaaskelainen AS, Pajunen M, Rauhala M, Kaleva-Kerola J, Salminen T, Leinonen M, Elomaa I, Isola J: Adjuvant docetaxel or vinorelbine with or without trastuzumab for breast cancer. N Engl J Med 2006;354:809-820.

15 National Institute of Health: Trastuzumab for 6 months or 1 year in treating women with nonmetastatic breast cancer that can be removed by surgery, October 2007; clinicaltrials. Gov/show/nct 00381901.

16 Lassarat S, Jootar S: Ongoing challenges of a global international patient assistance program. Ann Oncol 2006;17(suppl 8):viii43-viii46. 
17 Colleoni M, Maibach R: Breast international group newsletter. 2007;9:22.

-18 Zwitter M, Kovac V, Smrdel U, Kocijancic I, Segedin B, Vrankar M: Phase I-II trial of low-dose gemcitabine in prolonged infusion and cisplatin for advanced non-small cell lung cancer. Anticancer Drugs 2005;16:1129-1134.

19 Brand R, Capadano M, Tempero M: A phase I trial of weekly gemcitabine administered as a prolonged infusion in patients with pancreatic cancer and other solid tumors. Invest New Drugs 1997;15: 331-341.

20 Akrivakis K, Schmid P, Flath B, Schweigert M, Sezer O, Mergenthaler HG, Possinger K: Prolonged infusion of gemcitabine in stage iv breast cancer: a phase i study. Anticancer Drugs 1999;10:525-531.

21 Fossella FV, Lippman SM, Shin DM, Tarassoff P, Calayag-Jung M, Perez-Soler R, Lee JS, Murphy WK, Glisson B, Rivera E, Hong WK: Maximumtolerated dose defined for single-agent gemcitabine: a phase I dose-escalation study in chemotherapy-naive patients with advanced non-small-cel lung cancer. J Clin Oncol 1997;15: 310-316.

22 Abbruzzese JL, Grunewald R, Weeks EA, Gravel D, Adams T, Nowak B, Mineishi S, Tarassoff P, Satterlee W, Raber MN, et al.: A phase I clinical, plasma, and cellular pharmacology study of gemcitabine. J Clin Oncol 1991;9:491-498.

23 Ratain MJ, Cohen EE: The value meal: how to save $\$ 1,700$ per month or more on lapatinib. J Clin Oncol 2007;25:3397-3398.

24 Colleoni M, Orlando L, Sanna G, Rocca A, Maisonneuve P, Peruzzotti G, Ghisini R, Sandri MT, Zorzino L, Nole F, Viale G, Goldhirsch A: Metronomic low-dose oral cyclophosphamide and methotrexate plus or minus thalidomide in metastatic breast cancer: antitumor activity and biological effects. Ann Oncol 2006;17:232-238.

25 Puozzo C, Gridelli C, Jaworski M: Pharmacokinetics of navelbine oral in elderly patients. Tumori 2002;88:S75-76.

-26 Winer EP, Chu L, Spicer DV: Oral vinorelbine (navelbine) in the treatment of advanced breast cancer. Semin Oncol 1995;22:72-78; discussion 78-79.
27 Talbot DC, Moiseyenko V, Van Belle S, O'Reilly SM, Alba Conejo E, Ackland S, Eisenberg P, Melnychuk D, Pienkowski T, Burger HU, Laws S, Osterwalder B: Randomised, phase II trial comparing oral capecitabine (xeloda) with paclitaxel in patients with metastatic/advanced breast cancer pretreated with anthracyclines. Br J Cancer 2002;86: 1367-1372.

28 Sikora K, Advani S, Koroltchouk V, Magrath I, Levy L, Pinedo H, Schwartsmann G, Tattersall M, Yan S: Essential drugs for cancer therapy: a world health organization consultation. Ann Oncol 1999; 10:385-390.

29 WHO: Essential medicines who model list. Retrieved from: $w w w$. Who.Int/emlib, August 20, 2008.

30 Garber JE, Richardson A, Harris LN, Miron A, Silver D, Golshan M: New adjuvant cisplatin (cddp) in 'Triple-negative' Breast cancer (bc). San Antonio Breast Cancer Synposium 2006, abstr 3074.

31 Colleoni M, Rocca A, Sandri MT, Zorzino L, Masci G, Nole F, Peruzzotti G, Robertson C, Orlando L, Cinieri S, de BF, Viale G, Goldhirsch A: Low-dose oral methotrexate and cyclophosphamide in metastatic breast cancer: antitumor activity and correlation with vascular endothelial growth factor levels. Ann Oncol 2002;13:73-80.

32 Goetz MP, Rae JM, Suman VJ, Safgren SL, Ames MM, Visscher DW, Reynolds C, Couch FJ, Lingle WL, Flockhart DA, Desta Z, Perez EA, Ingle JN: Pharmacogenetics of tamoxifen biotransformation is associated with clinical outcomes of efficacy and hot flashes. J Clin Oncol 2005;23:9312-9318.

33 Zanger UM, Raimundo S, Eichelbaum M: Cytochrome p450 2d6: overview and update on pharmacology, genetics, biochemistry. Naunyn Schmiedebergs Arch Pharmacol 2004;369:23-37.

34 Toscano C, Klein K, Blievernicht J, Schaeffeler E, Saussele T, Raimundo S, Eichelbaum M, Schwab M, Zanger UM: Impaired expression of cyp2d6 in intermediate metabolizers carrying the *41 allele caused by the intronic snp $2988 \mathrm{~g}>\mathrm{a}$ : evidence for modulation of splicing events. Pharmacogenet Genomics 2006;16:755-766.
35 Schroth W, Antoniadou L, Fritz P, Schwab M, Muerdter T, Zanger UM, Simon W, Eichelbaum M, Brauch H: Breast cancer treatment outcome with adjuvant tamoxifen relative to patient cyp2d6 and cyp2c19 genotypes. J Clin Oncol 2007;25:51875193.

36 Punglia RS, Winer EP, Weeks JC, Burstein HC: Could treatment with tamoxifen be superior to aromatase inhibitors in early-stage breast cancer after pharmacogenomic testing? A modeling analysis. ASCO Ann Meet Proc Part 1, 2007,vol 25, pp. 502.

37 Bonanni B, Macis D, Maisonneuve P, Johansson HA, Gucciardo G, Oliviero P, Travaglini R, Muraca MG, Rotmensz N, Veronesi U, Decensi AU: Polymorphism in the cyp2d6 tamoxifen-metabolizing gene influences clinical effect but not hot flashes: data from the italian tamoxifen trial. J Clin Oncol 2006;24:3708-3709; author reply p. 3709.

38 Elzawawy AM, Elbahaie AM, Dawood SM, Elbahaie HM, Badran A: Delay in seeking medical advice and late presentation of female breast cancer patients in most of the world. Could we make changes? The experience of 23 years in Port Said, Egypt. Breast Care 2008;3:37-41.

39 WHO: National Cancer Control Programmes: Policies and Managerial Guidelines. Geneva, WHO, 2002.

40 Mellstedt H: Cancer initiatives in developing countries. Ann Oncol 2006;17(suppl 8):viii24-viii31.

41 Olopade OI, Schwartsmann G, Saijo N, Thomas CR Jr: Disparities in cancer care: a worldwide perspective and roadmap for change. J Clin Oncol 2006;24: 2135-2136.

42 Brauch H, Schroth W, Eichelbaum M, Schwab M, Harbeck N: Clinical relevance of cyp2d6 genetics for tamoxifen response in breast cancer. Breast Care 2008;3:43-50.

43 Siemiatycki J: Commentary: epidemiology on the side of the angels. Int $\mathrm{J}$ Epidemiol 2002;31: 1027-1029.

44 Chandiwana S, Ornbjerg N: Review of north-south and south-south cooperation and conditions necessary to sustain research capability in developing countries. J Health Popul Nutr 2003;21:288-297. 